\title{
Smart Attendance Control System Using GPS \& QR-Code
}

\author{
ASQR Team*, Nesma Abd El-Mawla**, Mohamed Ismaiel ${ }^{* *}$ \\ * Department of Communications and electronics, Nile Higher Institute for Engineering \\ and Technology, Egypt \\ ** Department of Communications and electronics, Delta Higher Institute for Engineering \\ and Technology, Egypt
}

DOI: 10.29322/IJSRP.11.07.2021.p11577

http://dx.doi.org/10.29322/IJSRP.11.07.2021.p11577

\begin{abstract}
Nowadays, smartphones play a significant role in our daily life. It has made life of every person simple and easier with different social, commercial, problem solving, educational and marketing apps etc., and in view of the necessity of social distancing after Covid-19, we have designed a system that deals with problem of attendance of students and employees in different institutions. Which they were using the paper purposed system to register their attendance. The proposed system is an attendance system based on the Internet of Things (IOT) technology, through the use of (Face ID - Fingerprint - QR code). Our system can be used in two types of organizations, the first one is for companies, and the attendance is registered through one of the available two features (Face ID or Fingerprint), and the system is also designed to control employee working hours. The second one is for educational institutions, and the system deals with managing and evaluating the attendance of all students. A (Face ID \& QR code) will be provided for students to take their attendance. The professor is responsible for determining the attendance of all students of the group or class. Users will need nothing more than their smartphone to confirm their attendance and departure
\end{abstract}

Index Terms- QR, System, Attendance, Technology.

\section{INTRODUCTION}

Regular attendance in all organizations, whether educational or at the corporate level, is necessary to improve the efficiency of the organization, and in light of the conditions that the world is suffering from due to Covid19, in addition to the traditional means used by institutions at the present time, such as fingerprint devices and paper, which were causing congestion when completing attendance processes And this process takes a long time, especially when the numbers are large, and in light of the current circumstances and with the spread of Covid-19 and the need to achieve social distancing, it was necessary to have an easy solution that ensures the accuracy and speed of the processes of attendance and departure of employees while maintaining their safety and saving time and effort to complete this process. That is why we thought of developing an easy-to-use application to record attendance and leave processes for all students and employees.

Attendance management system is an easy-to-use smart system based on (Face ID - Fingerprint - QR code) to record the attendance and departure of all students and employees, in addition to integrating an Android device with databases to store attendance results, moreover, analyzing attendance on a weekly and monthly basis and the main objective of the automated attendance system It is calculating the traditional method for recording attendance and providing an efficient and secure method for tracking attendance in organizations. 
Both the employee and the student will get a free mobile application that they use to take attendance and leave. The main objective of the Automated Attendance System is to computerize the traditional way of recording attendance and provide an efficient and automated way to track attendance in organizations.

There is a strong need to develop an intelligent attendance system. The proposed system is easy to use and smart based on (Face ID - Fingerprint - QR code) to record attendance and leave processes for all students and employees, in addition to integrating an Android device with databases to store attendance results, moreover, analyzing attendance on a weekly and monthly basis and the main objective of the system Automated attendance is computing the traditional way of recording attendance and providing an effective and secure way to track attendance in organizations. Also, the proposed system has many contributions in the field of attendance control technology (i) Ease of use compared to other systems (ii) Higher security (iii) Support for face recognition (iv) Ease of system maintenance (v) Get the result quickly (vi) Accuracy and efficiency (vii) Easy and simple user interface (viii) Environmentally friendly system as it increases sustainability by reducing paper waste (ix) Accuracy and fairness for college students and employees in the work environment (x) Takes less time and effort instead of others like scan code systems Optically (e.g. barcode, RFID...etc.)

The Remainder of this paper is organized as follows: an overview of QR technology and its different applications, followed by what QR could present for the world. After that, related researches and existing QR projects followed by QR challenges and future research directions. Further, an overview of QR technology and its different applications, followed by what QR could present for the world. After that, related researches and existing QR projects followed by QR challenges and future research directions. finally, the paper is concluded and gives a summary of the future work in the last section.

\section{LITERATURE SURVEY}

There are numerous recommendations for Automatic Attendance Systems in the writing and on the lookout. The majority of them do zero in on applications to be introduced on the speaker gadget, regardless of whether a cell phone or a PC. First system is a software to be introduced in the educator's cell phone. It empowers it to question understudies' cell phone by means of Bluetooth association and, through exchange of understudies' cell phones' Media Access Control (MAC) delivers to the educator's cell phone; presence of the understudy can be affirmed.

Furthermore, the second one uses continuous face discovery calculations coordinated on a current Learning Management System (LMS). It naturally distinguishes and enrolls understudies going to on a talk. The framework speaks to a supplemental device for educators, consolidating calculations utilized in AI with versatile strategies used to follow facial changes during a more drawn out timeframe.

While the third one is using unique mark check procedure. The framework where unique mark check is finished by utilizing extraction of particulars strategy and the framework that computerizes the entire cycle of gauging participation. Since biometrics is worried about the estimations of one of a kind human physiological or social attributes, the innovation has been utilized to check the personality of clients. It is getting basic to have the option to screen the presence of the validated client all through a meeting. In many recommendations, applications being utilized by the educator during class. Thus, on the off chance that the participation framework requires some activity from the teacher, at that point the class time will be upset each time the educator permits some late understudies into the class. In traditional technique where participation register is utilized both understudy's just as teacher's time is burned-through in gauging participation [1-3]. Then again, our proposition requires the teacher to do nothing extra past introducing the slides of the course to the understudies. Subsequently, understudies may enlist their quality whenever they wish during the class, while having at the top of the priority list that enrollment times are recorded [4].

However, QR code is a machine-intelligible code comprising of a variety of high contrast squares, regularly utilized for putting away URLs or other data for perusing by the camera on a cell phone. Figure 1 shows the QR code produced plan. QR has many different types could be listed as (i) Micro QR Code: is a more modest adaptation of the QR code standard for applications where image size is restricted and can hold 35 numeric characters. (ii) iQR Code: iQR codes 
can be made in choice to square or rectangular developments. This is proposed for circumstances where a rectangular standardized identification would somehow or another is more fitting, like barrel shaped items. (iii) SQRC Code: Secure Quick Response Code (SQRC) is a sort of QR code that contains "private information". This can be utilized to store private data and to deal with organizations inside data [5-9].

Nowadays, Global Navigation Satellite Systems, (GNSS) beneficiaries are getting increasingly touchier because of interminable advancement in chip innovation and handling power. High Sensitivity GNSS beneficiaries can get satellite signs in most indoor conditions and endeavors to decide the 3D position inside have been fruitful [10]. Other than expanding the affectability of the collectors, the procedure of A-GPS can be utilized, where the chronological registry and other data are moved through a cell phone. Besides, as advanced mobile phones embrace consistently on, universal area, area based sensor combination will turn into a standard element [11]. Furthermore, this helps in the proposed project to verify the user data reliability and check whether if he is in the exact location or not.

Moreover, Social media plays a very important role in the lives of users, and with the development of technologies for smart and sophisticated devices that are used daily, such as smart phones, which secure the Internet, the user has become open all the time on the Internet, and for this we find that the rapid response code technology is one of those technologies that allow the user to quickly access For its services, which require very little storage memory on smartphones, this is why it has become more popular with various companies, and examples of quick response codes are: QR Code is an abbreviation of the English word Quick Response code, which means a quick response code, it is a two-dimensional code designed first by Denso, a subsidiary of Toyota, with the aim of facilitating tracking cars during the manufacturing cycle, then spreading in all areas due to the advantages it provides and the volume of data that it can Stored. The QR code consists of black units arranged in a specific shape on a white square background, scanning them reveals the data that they symbolize.

As previously mentioned, the QR code can be employed in almost all fields, and thus we find it present in the automotive industry, commercial tracking of goods, transportation tickets and product price definition, and it is also used extensively by companies as a practical and fast way to access their websites, Through the mobile tag feature, it suffices to indicate that the month of June 2011 witnessed the use of 14 million rapid response codes in the United States of America alone, so that we realize the importance of this new technology and the extent of its penetration in our daily life.

There are many creative ideas in which QR Code can be employed as in 2017: A group of students using QR Code technology improves office services (field study at the Faculty of Science and Technology Library at Mohammed Khudair. Biskra) was aimed at facilitating access to the content of the sources with the possibility of loading the summary or bibliographic data for each container at the Faculty of Science and Technology Library.

If we shed light on the economic, social, or educational (academic) field in general, we will realize the extent of its need to introduce modern technology in the conduct of services. And we will find that in light of the conditions that the world suffers from due to Covid-19, we urgently need to apply this technology in companies and educational institutions in order to achieve divergence. Social and privacy of working people and preventing touching hands between students, so we worked to design a system that deals with the problem of attendance registration and departure for students and employees in different institutions through their smartphones. Thus, we will work to achieve leadership in the field of institutional technological development in Egypt and the Middle East. 


\section{WORK OVERVIEW}

\section{Application system in companies}

The employee is the first time he makes a login, so the application asks him to imagine five images, the five images he takes pictures of and sends them to be registered in the Database so that we make a reference with the five images that we know we work on the basis of the face recognition. This is how Login is for the first time. When the login is done, every time he checks the name and password of the employee is correct, he will set it up; an error will ask him to enter them again. Each account with a name and password will be from one device only. The application takes the id from his mobile phone (in reality, you are known by the human fingerprint) and each Android mobile has its own ID that distinguishes it from any other mobile.

When the employee enters his account from his mobile for the first time, his account is registered on it, and he is not allowed to register from the mobile of any other employee. And there are two ways to attend. He does a face recognition, so he takes a picture of himself and sends it to the server, and the server makes sure he and he doesn't, or by the way of the finger print that he works check in or check out, provided that the employee is inside the workplace because the step is done because in GPS he determines the location of the work and his location must be In the workplace to know the attendance record.

With regard to the sheets, each employee has the right to know his own Sheet to know the number of times he attends in the month, and the sheet system provides him with knowing how to check in his nation or check out his nation and the number of hours between them, and he has a wage, whether throughout the month or day while the manager has the right to see the staff's sheets. The system has two main cases as following: (i) In the case of the employee to a person who wants to bring himself, but his mobile phone, for example, is lost and wants to check in and check out. The only one who can bring him is the director, so he says to one of the managers that I want to check in and check out in a feature in the manager's account that he can bring him through him. (ii) In the event that the employee buys a new mobile, the first time he login in, he will know that he has brought a new mobile, and he will take the Android ID of the new mobile and put the place of the old mobile, meaning he will recognize you and register the new mobile in the name of your account.

\section{(B) Application system in Educational institutions}

The student makes a login for the first time, the application asks him to imagine five images, the five images are photographed and sent and they are registered in the data base, so that we make a reference with the five images that we know we work on the basis of face recognition. This is a login for the first time, when the login is made every time it checks the name and password. With the right student, he will pass him, wrong; he will ask him to enter them again. Each account with a name and password will be from one device only. The application takes the id of its mobile phone (in reality you know the human fingerprint) and each mobile has its own Android ID that distinguishes it from any other mobile. When the student enters his account from his mobile for the first time, his account is registered on it, and he is not allowed to register from the mobile of any other student.

The process is how: The professor login into the application, the application checks whether the professor is the professor or not, and then the professor enters his lecture data and sends the request to the server. The server will make a QR code with the information that the professor gave him. For example, the professor chooses a lecture of such and such material and sends the data to the server, and accordingly the server will make a QR Code with the data and send it, so the professor has a QR Code for the lecture, for example, who will explain it now, and present it to the students, for example, on the power point or whoever the student is when he comes to press the buttons to enter the QR Code will ask him the first Face recognition in order for the first to confirm that the student owns the count. If the Face recognition is correct, the student will be infected and the student 
will scan the QR Code. An error will be recorded, the absence will be recorded, and the process will be concluded. The time available for the student to scan the QR code is ten minutes.

For sheets, each student has his own sheet, through which he knows the number of lectures that have been attended over the course of the term and the number of times he has been absent easily. The professor has the right to simply look at the students' sheets. (i) In the case of the student who wants to attend himself but his mobile is lost, the only one who can make him attend is the professor, and he goes to the professor and says I want to do a QR code scan because there is a feature in the professor's account that he can bring it through it. (ii) In the event that the student buys a new mobile, the first time he login in, he will know that he has brought a new mobile, and he will take the Android ID of the new mobile and put the place of the old mobile, meaning he will recognize you and register the new mobile in the name of your account.

\section{DESIGN DIAGRAMS}

In the presented research, (Face ID - Fingerprint - QR code) technology will be used in a simple way to facilitate the attendance and departure process for employees and the follow-up process for managers, as well as for students when taking the absence process to find out who attended the lecture / lab / educational program by a system without the need for any external devices. Figures 1 and 2 shows the component diagram of the presented system.

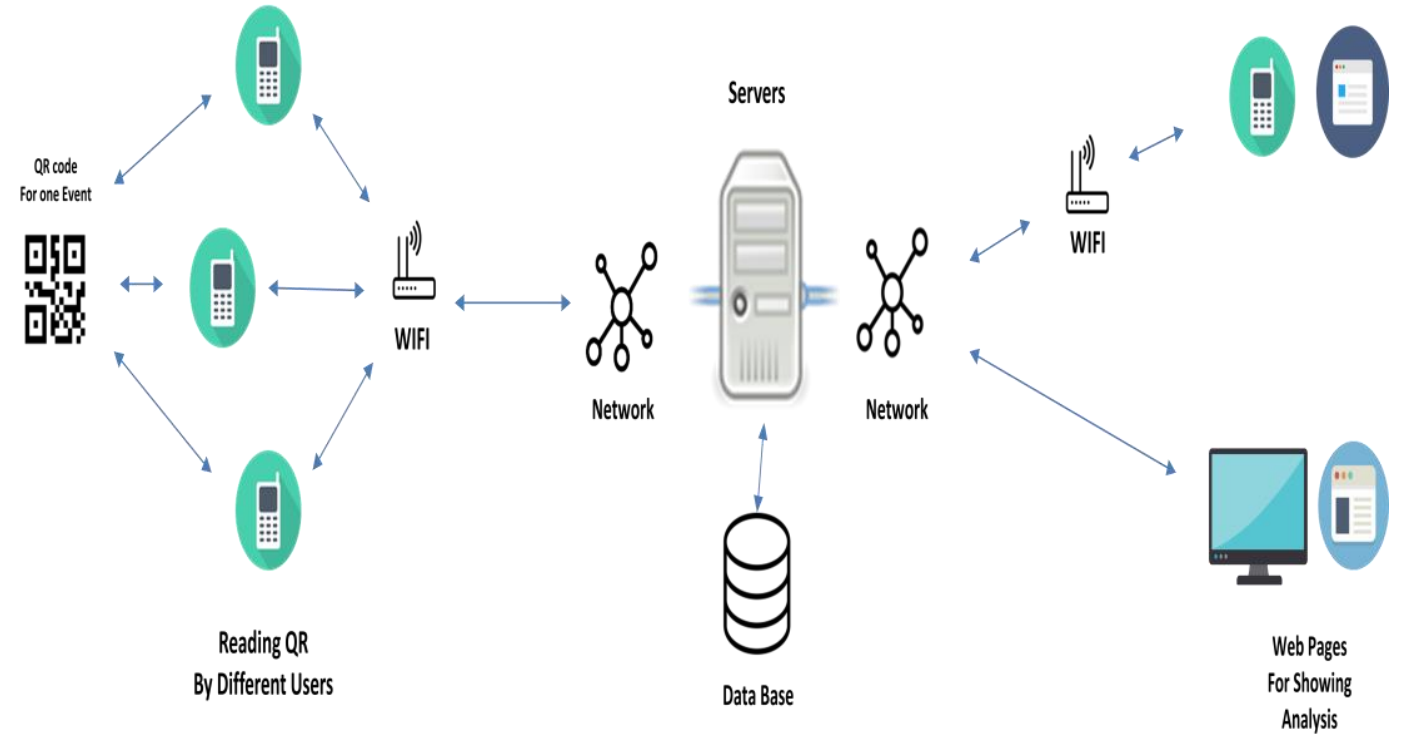

Figure 1. Overall System Design. 

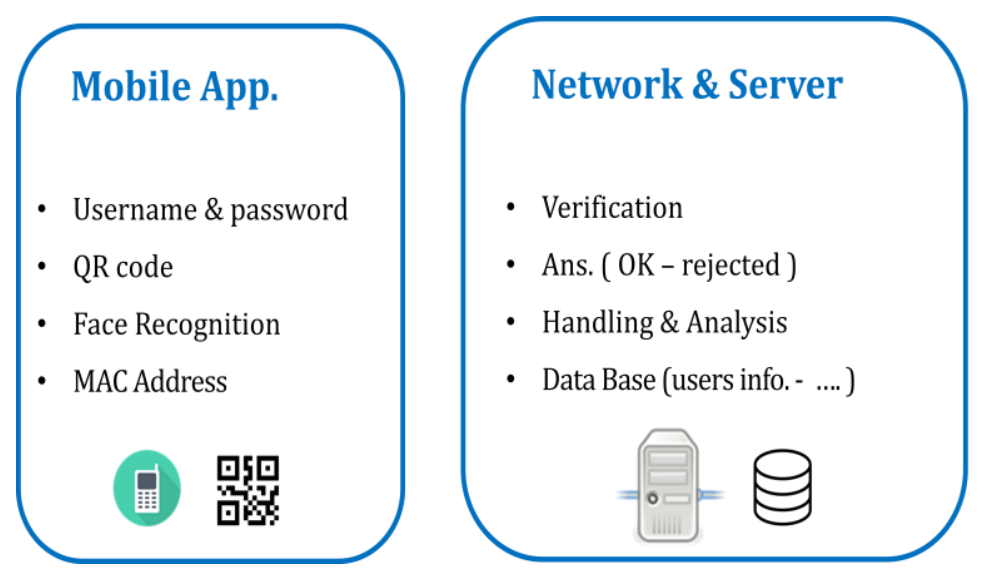

\section{Web Pages}

- QR code Generator

- Staff Showing Analysis

- Student Showing

Analysis

Figure 2. System Internal Structure.

\section{A. System Flowchart}

Flowcharts are graphical representations of the steps. It originated from computer science as a tool for representing algorithms and programming logic, but has expanded for use in all kinds of other processes. Nowadays, flowcharts play a very important role in displaying information and aiding in thinking. They help us visualize complex processes, or clarify the structure of problems and tasks. A flowchart can also be used to define a process or project to be executed. Figure 3 shows the flow chart diagram of the presented system. 


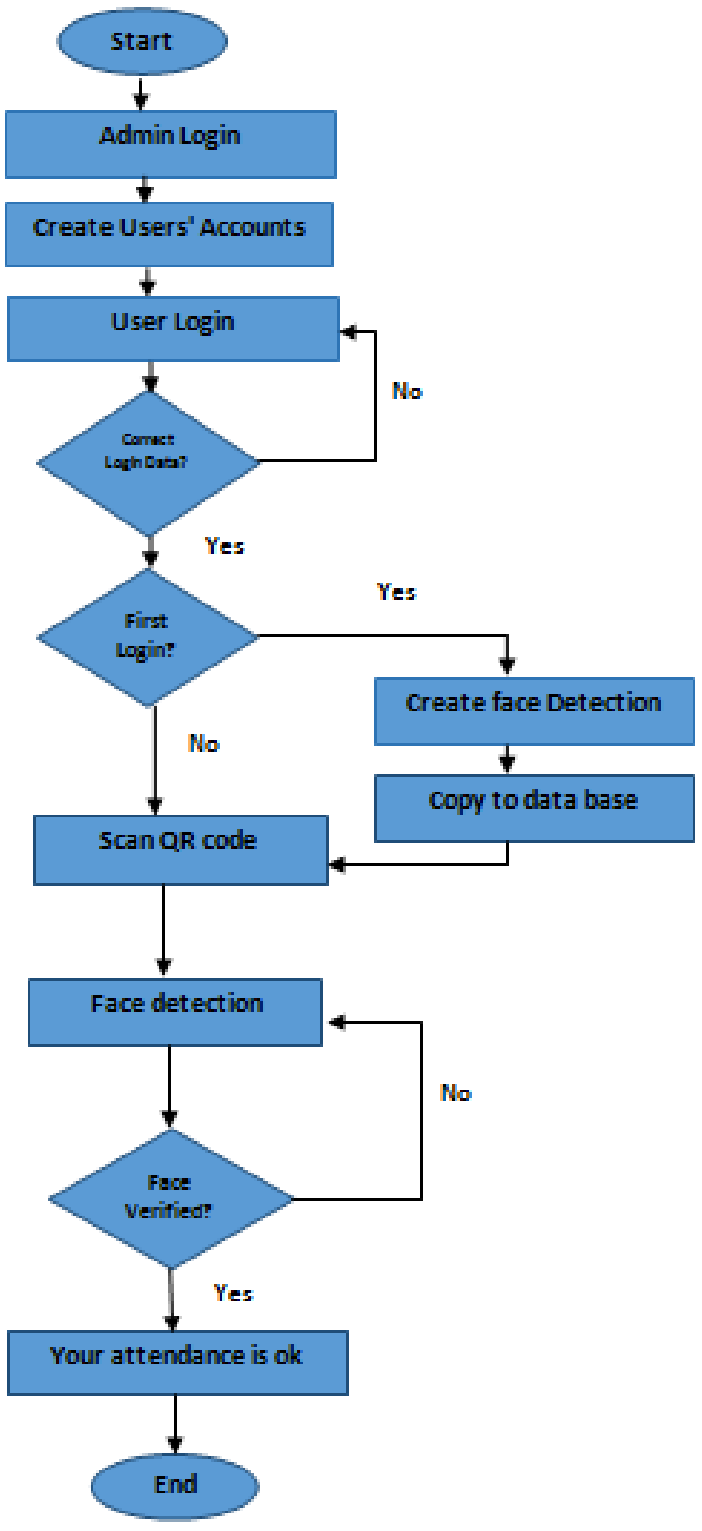

(a) Student Point of view 


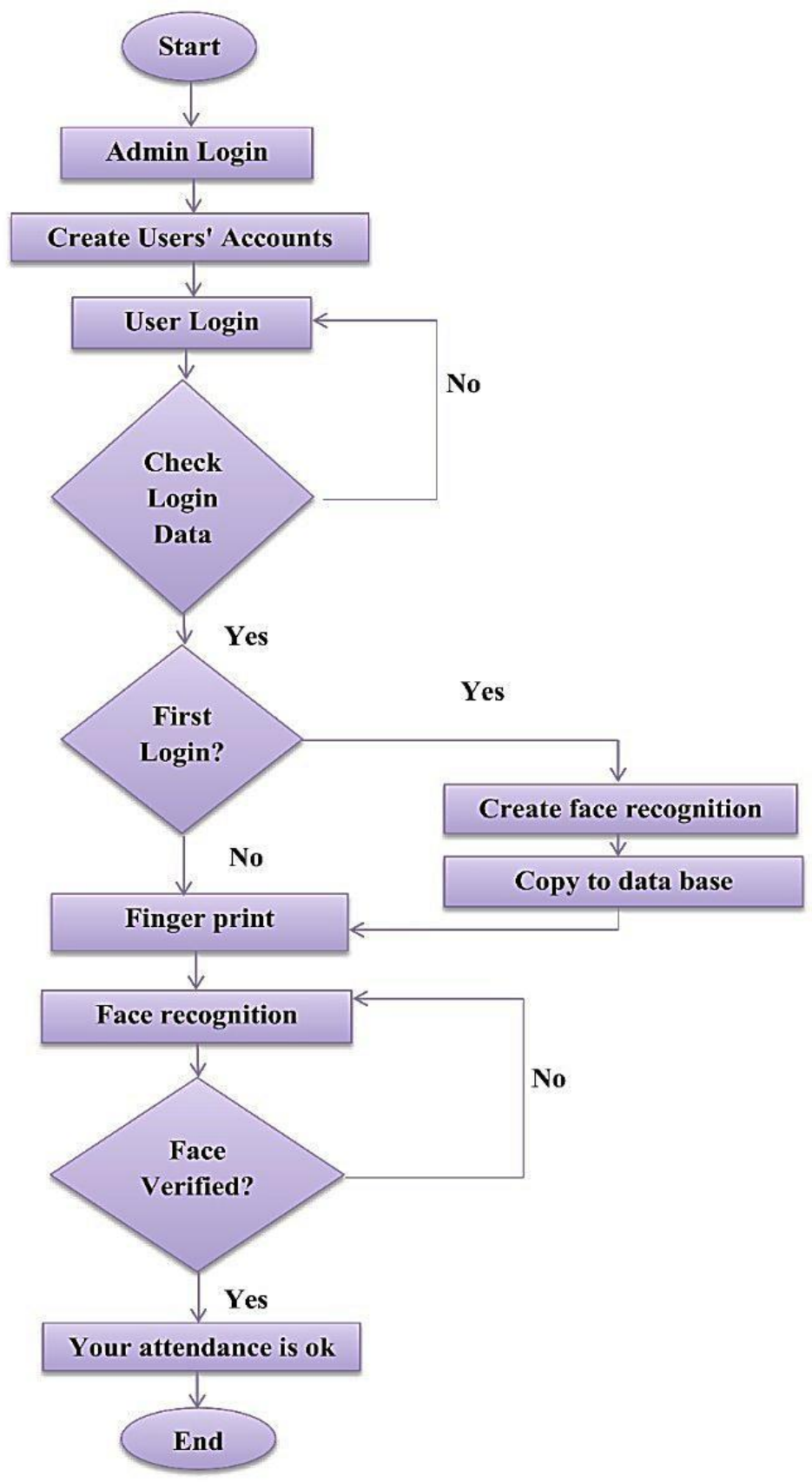

(b) Company Point of View

Figure 3. System Flowchart.

\section{B. Use Case Diagram}

A use case diagram consists of six graphical elements that represent the entire system: systems, user, use cases, association, dependencies, and generalization. Figure 4 describes the use case diagram of the presented system. 


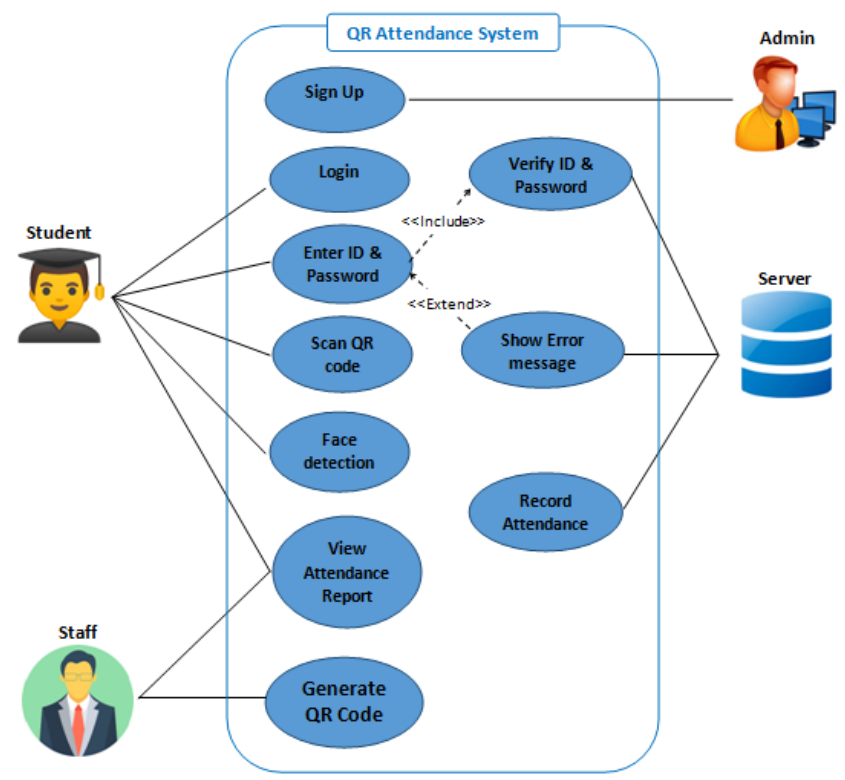

(a) Faculty Point of View

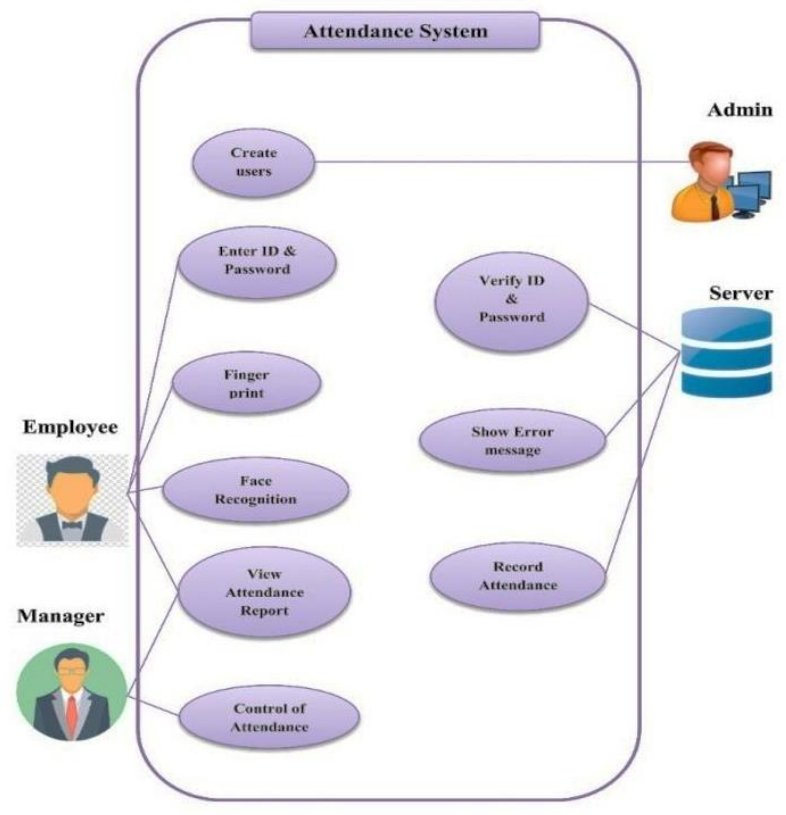

(b) Company Point of View

Figure 4. System Use Case Diagram.

\section{Data Flow Diagram}

Data flow is a pathway through which data travels from one part of an information system to another. The data flow may represent a single data element such as a student ID or it can represent a group of data element (or data structure). Figure 5 describes the data flow diagram of the presented system. 


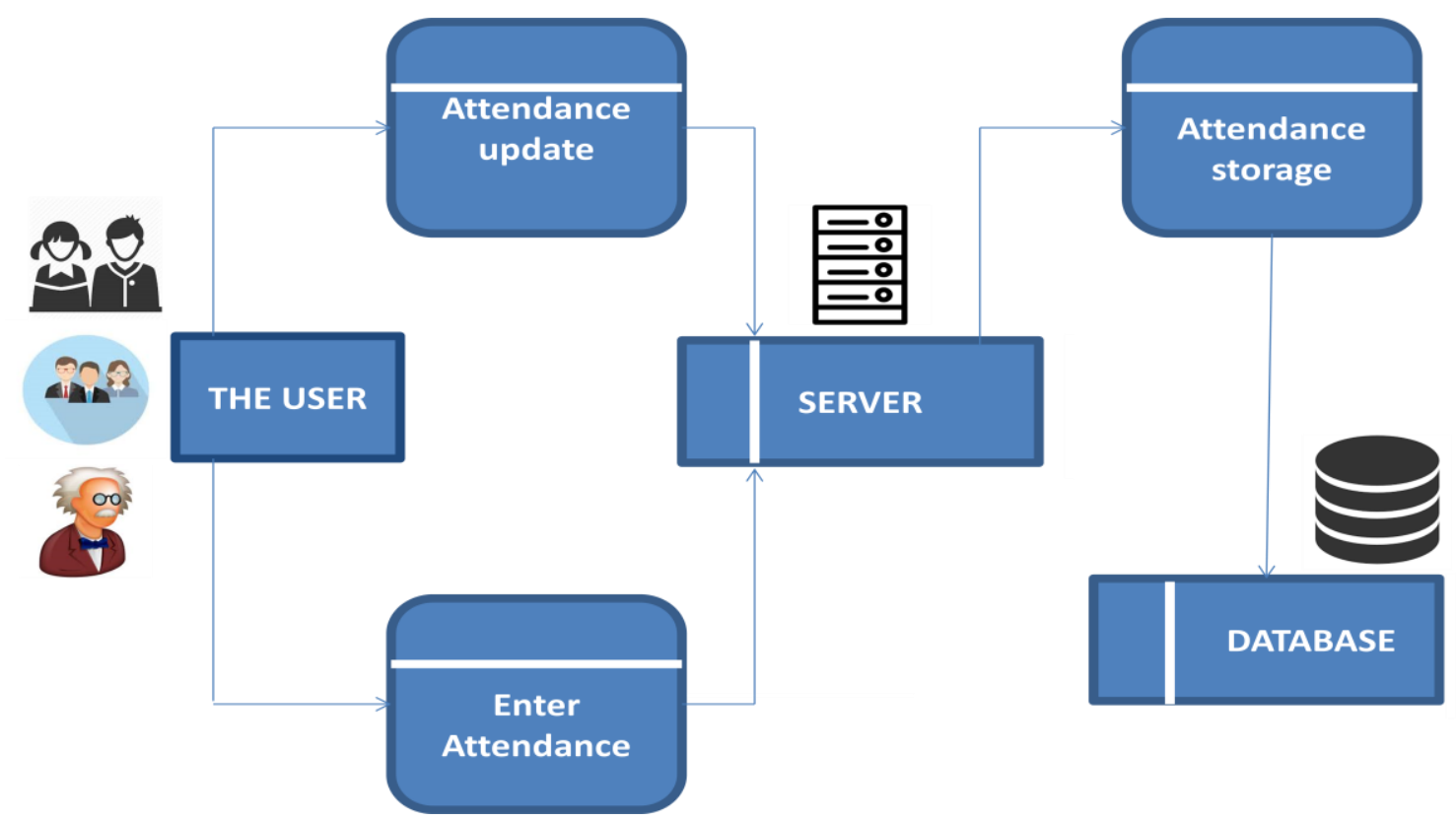

Figure 5. System Data Flow Diagram.

\section{Sequence Diagram}

It is a model for the high-level interaction between active organisms in a system. A sequence diagram is a model for the interaction of instances of an object within a use-case collaboration. A model for interaction between organisms within a collaboration that achieves a process. Either a general interactions model (showing all possible paths through an interaction) or specific states of a reaction (showing only one pathway through an interaction. Figure 6 describes a sequence diagram of the intro system. 


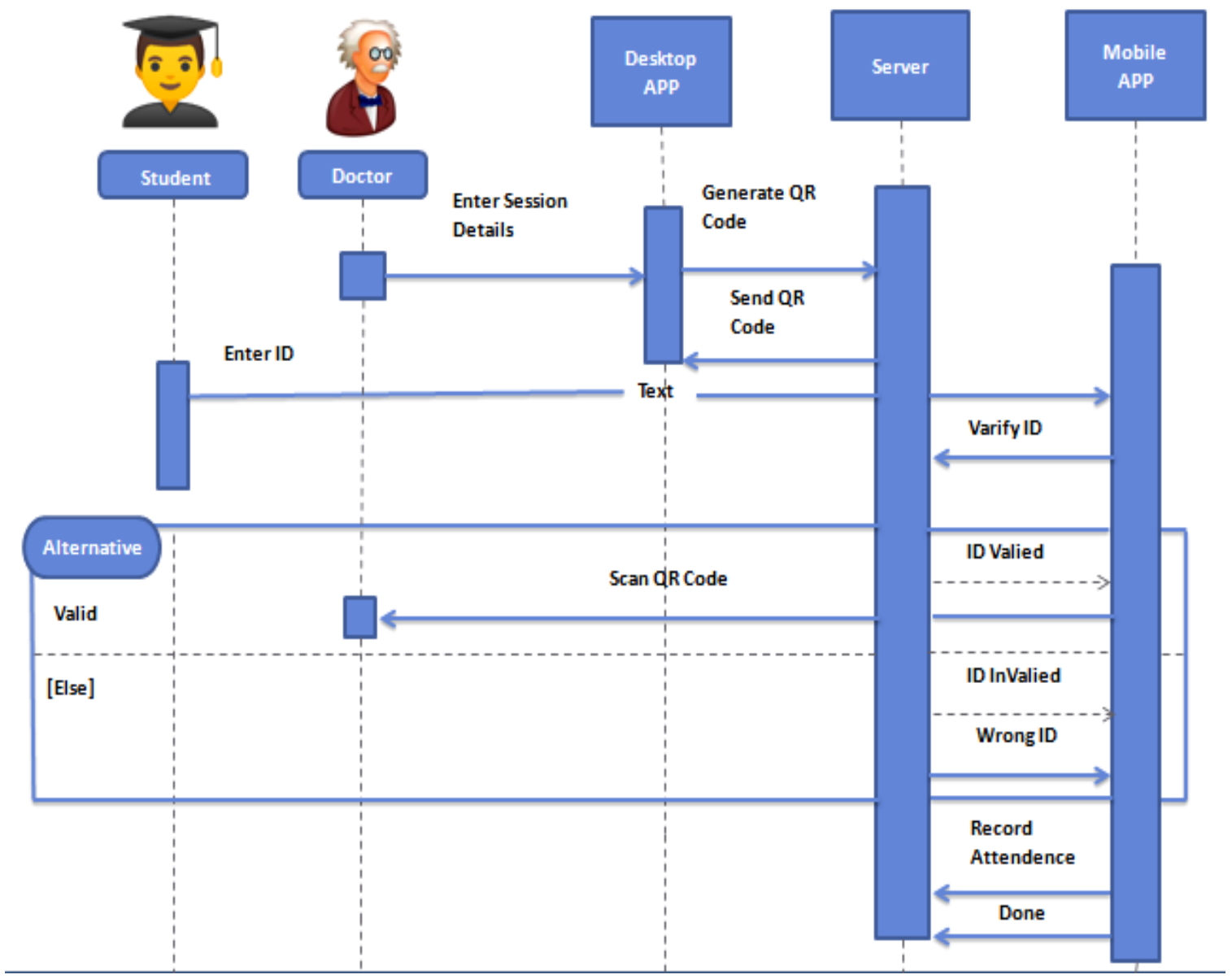

Figure 6. System Sequence Diagram

\section{APPLICATION LAYOUTS \& IMPLEMENTATION}

The mobile application of the proposed system mainly consists of a number of layouts (i) staff layouts; (ii) student layouts; (iii) report layouts. Student and employee layouts implicitly consist of other layouts. The first is for login: it consists of two plain texts to enter the username and password and the login button that clicks, we will be in the second layout. The second is scanning the QR code. It will be able to access the camera to read the QR code at students and the third is designed for face detection. Generating QR is done based on QRCODE library of JS then used over android system [12-15]. It will be able to detect the student's face and analyze the data. As for the employees, they will be assigned a fingerprint $\&$ face-id. Figure 7 shows different layouts of the system. 

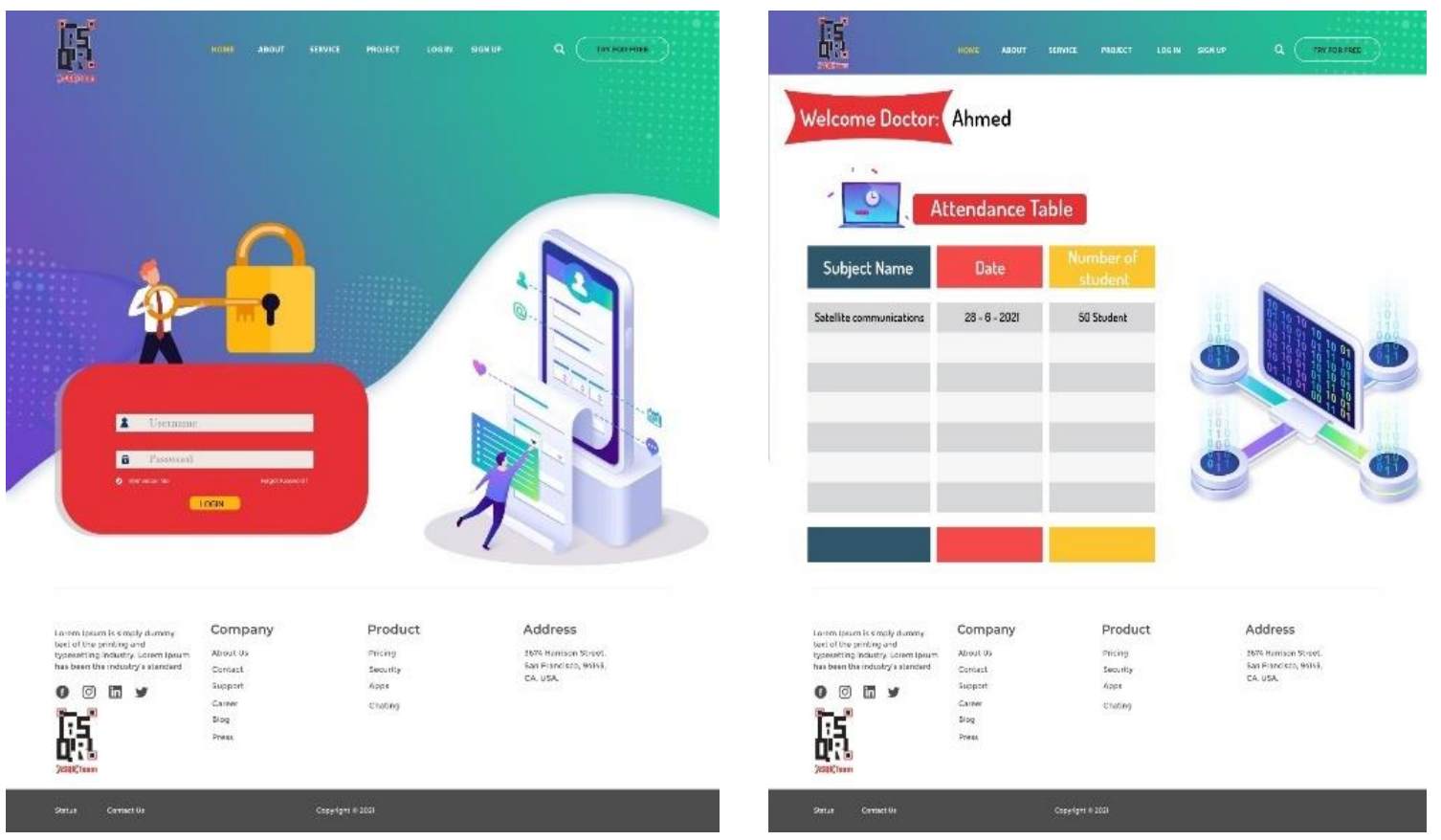

(a) Webpages
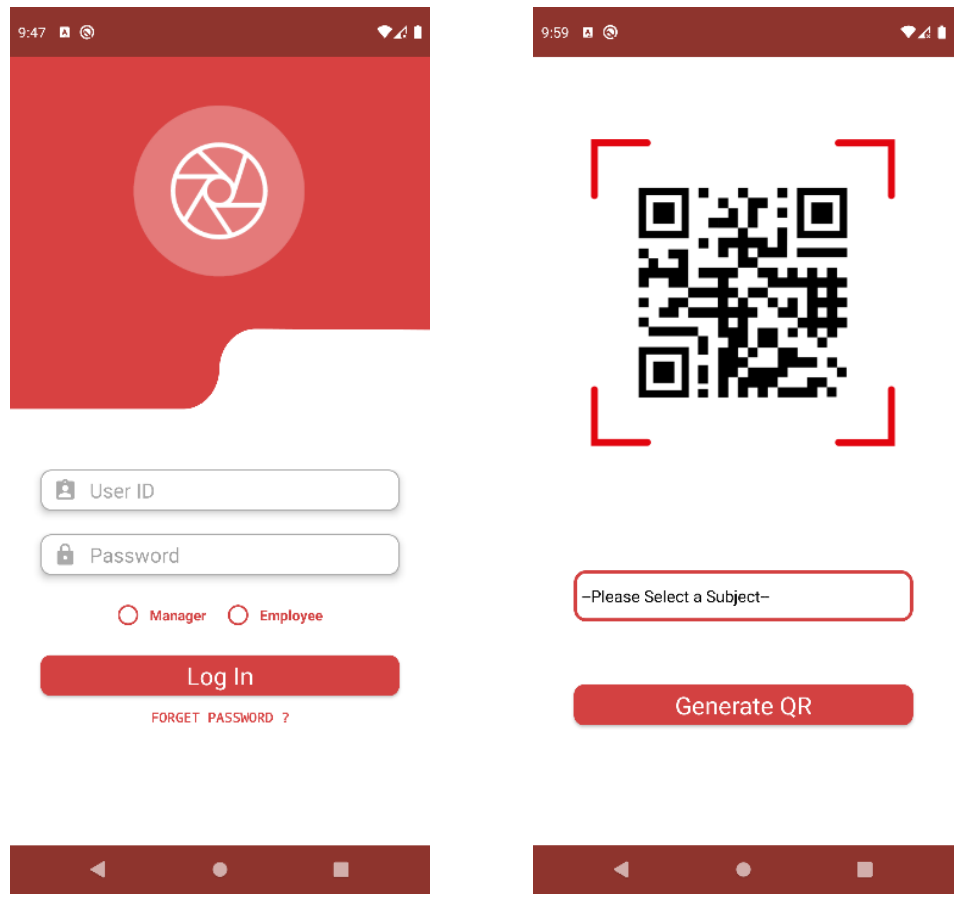

\begin{tabular}{|c|c|c|c|c|}
\hline $27 \times 6$ & & & & 8 \\
\hline & & ser Id: on & & \\
\hline Date & Time in & Time out & $\begin{array}{l}\text { Work } \\
\text { Time }\end{array}$ & State \\
\hline 1 may & - & . & . & $\theta$ \\
\hline 2 may & . & . & & $\boldsymbol{\theta}$ \\
\hline 3 may & - & $\cdot$ & & $\theta$ \\
\hline 4 may & & . & & $\theta$ \\
\hline 5 may & - & . & & $\theta$ \\
\hline 6 may & & . & & $\theta$ \\
\hline 7 may & - & . & & $\otimes$ \\
\hline 8 may & & . & & $\boldsymbol{\theta}$ \\
\hline 9 may & . & . & . & $\theta$ \\
\hline 10 may & - & . & - & $\boldsymbol{\theta}$ \\
\hline 11 may & & . & & $\otimes$ \\
\hline 12 may & & . & & $\theta$ \\
\hline 13 may & & . & & $\otimes$ \\
\hline 14 may & - & . & - & $\theta$ \\
\hline 15 may & & . & & $\theta$ \\
\hline 16 may & . & . & . & $\theta$ \\
\hline 17 may & & 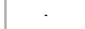 & & $\otimes$ \\
\hline in man. & & & & a \\
\hline GET & SHEETS & Mas & & \\
\hline & & $\bullet$ & & \\
\hline
\end{tabular}

(b) Mobile App.

Figure 7. System Layouts for Mobile App.

\section{WORK SCENARIO INSIDE THE APPLICATION}

The Scenario clarifies all the steps from installing the app until the user attends on the system. After installing the app, our user will face an activity only at the first time he use the app which will ask him which organization he targets, and according to his selection we select to him the track that he will follows it inside the app. If the user press on the company selection button, the app enters him to login activity and ask him 
again if he is an employee or a manager, and based on that we will define the power of each of them, And before the user begins to prepare himself on the system, the application will ask permission to verify his location whether he is inside the company or not.

After verifying the location and the result is correct, the application will allow him to register his attendance on the system using any of the features available in the application such as fingerprint or facial recognition. And if the result of the location verification is wrong, the application will not allow him to register his attendance on the system. At the end of the day, he can look at his worksheet to follow up on his attendance. Note: The application does not allow to the user to register his attendance twice a day, and this is one of the strengths of the system.

Further, if user presses the university selection button, the user will enter to the login activity and be asked whether he is a professor or a student. And also the application will show the specific permissions for each of them. The professor generates the QR Code and has the right to see the attendance sheet of his students. As for the student, he scans the QR Code that was generated by the doctor, and prepares himself on the system. And both the professor and the student have the right to see the sheet of their attendance. Also, before the professor or the student uses the application, they must check their location to allow them to use the application.

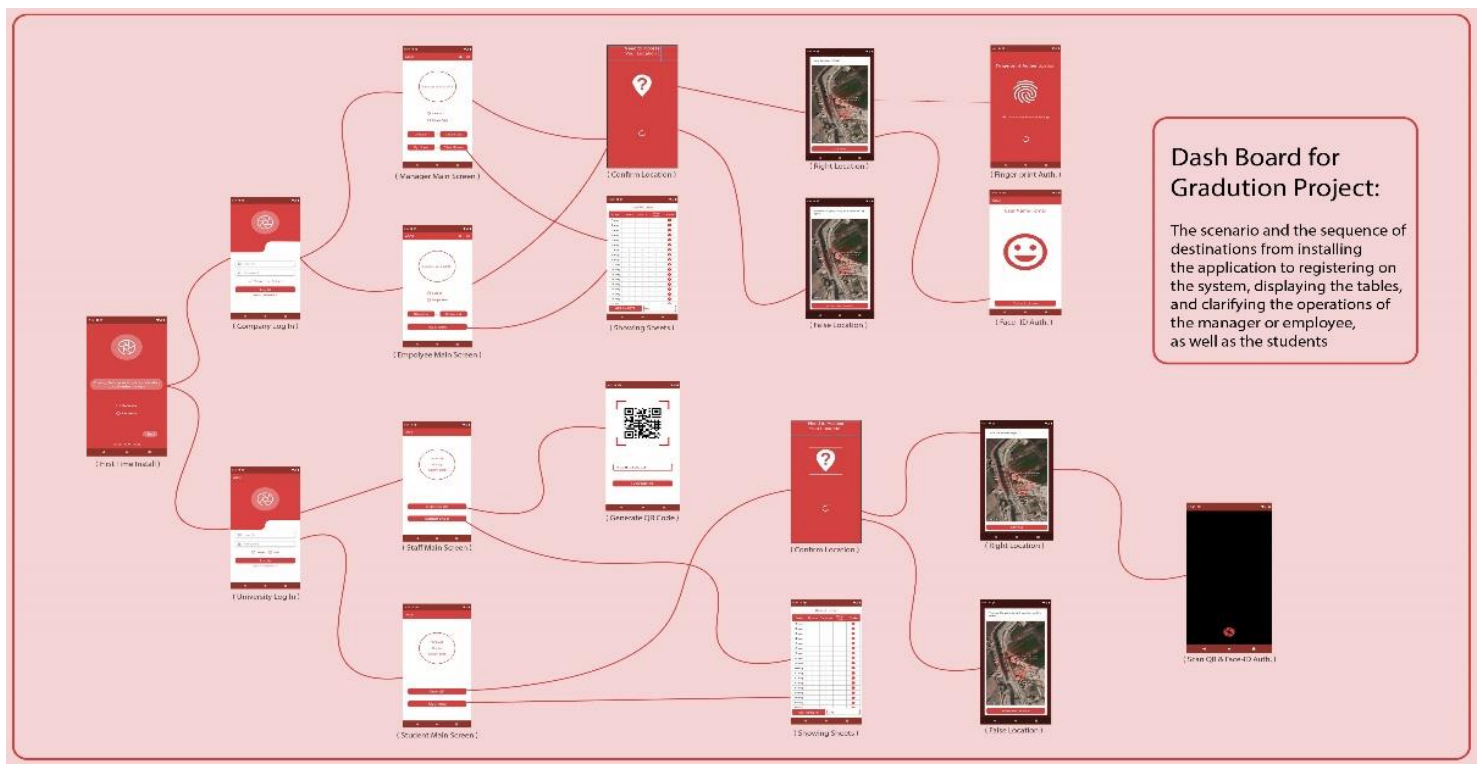

Figure 8. Application Scenario.

\section{CONCLUSION AND FUTURE WORK}

Introducing a new system to save time and effort in attendance and leave operations in the country and to achieve social distancing and privacy for working people in light of the current global conditions and Covid-19. In addition, the attendance and monitoring system is very important in our daily lives. An easy-to-use and smart system based on (Face ID - Fingerprint - QR code) has been developed to record leave attendance processes for all students and employees, in addition to integrating an Android device with databases to store attendance results, moreover, attendance analysis on a weekly and monthly basis and the main objective of Automated attendance system is to computerize the traditional way of recording attendance and provide an efficient and secure way to track attendance in enterprises. The QR code based smart attendance system is the most accurate among other scan code technologies. In this project, we will develop an attendance monitoring system and make progress in storing attendance in smartphones instead of wasting paperwork to save our planet's resources 
and engage more in environmentally friendly concepts. Our future work will focus on expanding the system to support factories and companies with large numbers of workers who need attendance monitoring. We will also provide safer and improved options. Finally we conclude, if we combine this attendance monitoring system with the financial system tool of any company, hotel or resort, the system will solve the problem of global attendance in real time as it will reduce the time and efforts required for the check-in / check-out process.

\section{ACKNOWLEDGMENT}

We would like to thank our colleagues who provided encourage, expertise and insight that greatly assisted the research. Also, we feel grateful to Nile Higher Institute for Engineering \& Technology as this work was supported in part by it.

\section{REFERENCES}

[1] Ashwini C. Ingle, Ishwar S. Jadhav , S.R.Pachpande , J.P.Chaudhari, "Comprehensive Survey on Automatic Embedded Attendance System," IOSR Journal of Computer Engineering (IOSR-JCE) e-ISSN: 2278-0661,p-ISSN: 2278-8727, Volume 18, Issue 5, Ver. V (Sep. - Oct. 2016), PP 86-93

[2] Dr Suvarna Nandyal, "An Automatic Attendance System Using Image processing” The International Journal of Engineering and Science (IJES) Volume 4 Issue 11, 2015.

[3] D.Narendar Singh, Chaitanya kumar Munukoti, "Attendance Monitoring System Using ARM9 with QR Code," International Journal of Latest Trends in Engineering and Technology (IJLTET), Vol. 2, Issue 1, January 2013

[4] J. O. Odiete, A. O. Agbeyangi \& O. Olatinwo, "An Automated Door Control System using Biometric Technology," IOSR Journal of Computer Engineering (IOSR-JCE) e-ISSN: 2278-0661,p-ISSN: 2278-8727, Volume 19, Issue 4, Ver. I (Jul - Aug 2017), PP 20-25

[5] Aryachandran S., Jyothi R L, "Secure Color QR Codes," IOSR Journal of Computer Engineering (IOSR-JCE) e-ISSN: 2278,0661p-ISSN: 2278-8727, PP 77-85.

[6] Hiroko Kato and Keng T. Tan, "Pervasive 2D Barcodes for Camera Phone Applications":, IEEE Computer Society 15361268/07/2007 IEEE

[7] W. Chen, G. Yang and G. Zhang: "A Simple and Efficient Image Pre-processing for QRDecoder":2nd International Conference on Electronic \& Mechanical Engineering and Information Technology (EMEIT2012).

[8] Y. Liu and M. Liu: "Automatic Recognition Algorithm of Quick Response Code Basedon Embedded System": Proceedings of the Sixth International Conference on Intelligent Systems Design and Applications (ISDA'06).

[9] K.Nurwono,R.Kosala:"Color Quick Response Code For Mobile Content Distribution": in Proc. 7th Int. Conf. Adv. Mob. Comput. Multimedia, Dec. 2009, pp. 267-271.

[10] B.V.Santhosh Krishna, "GPS and GPRS BASED AUTOMATED ATTENDANCE SYSTEM," International Journal of Engineering Science and Technology, Vol. 2 (12), 2010, 7449-7458.

[11] Harsh Shinde, Gaurav Raul, Sagar Sherk, Amruta Sanki, "GPS Based Attendance Management System with RFID Technology", International Journal of Engineering Research and Technology (IJERT) ISSN: 2278-0181 Published by www.ijert.org ICIATE 2017 Conference Proceedings.

[12] “Android tutorials" [Online]. Available: https://developer.android.com/training/index.html

[13] "Android tutorials" [Online]. Available: https://www.tutorialspoint.com/android/

[14] "About Bar Code" [Online]. Available:http://files.microscan.com/whitepapers/barcode_basics.pdf

[15] "ISS QR Code AIM Store: Historical Archive" [Online]. Available: Aimglobal.org

[16] "QR code integration with Android" [Online]. Available: https://github.com/zxing/zxing

\section{AUTHORS}

First Author - ASQR Team, qualifications, Nile Higher Institute for Engineering and Technology.

Second Author - Nesma Abd El-Mawla,Teaching assistant, Nile Higher Institute for Engineering and Technology, nesma.abdelmawla@nilehi.edu.eg.

Second Author - Mohamed Ismaiel, Adjunct Professor, Delta Higher Institute for Engineering and Technology, mi5668054@gmail.com. 
Corresponding Author - Nesma Abd El-Mawla,Teaching assistant, Nile Higher Institute for Engineering and Technology, nesma.abdelmawla@ nilehi.edu.eg. 